\title{
Study on the degree of knowledge of dental colour's characteristics in relation to the dentist's professional experience
}

\author{
Studiu asupra gradului de cunoaștere a caracteristicilor culorii dentare \\ raportat la experiența profesională a medicilor stomatologi
}

\author{
Ana Maria Cristina Țâncu' ${ }^{1}$, Irina Șerbănoiu², Mihaela Pantea ${ }^{3}$, Alexandra Totan", \\ Elena Preoteasa', Marina Meleșcanu Imre ${ }^{1}$ \\ ${ }^{1}$ Disciplina Protezare Totală, Facultatea de Medicină Dentară, UMF „Carol Davila“, București, România \\ ${ }^{2}$ Practică Privată, București, România \\ ${ }^{3}$ Disciplina Protetică Dentară Fixă și Ocluzologie, Facultatea de Medicină Dentară, UMF „Carol Davila“, \\ București, România \\ ${ }^{4}$ Disciplina Biochimie, Facultatea de Medicină Dentară, UMF „Carol Davila“, București, România
}

\begin{abstract}
Aim. Our study focused on the analysis of the degree of kwowledgetof the dental colour's characteristics, by the dentists regarding the hue, chroma and value, for dentures wearer edentulous patients, and their knowledge in this field, in correlations with some factors.

Material and method. 50 dentists, with a variable number of years of professional experience, between 24 and 54 years old, feminine in majority, formed the lot of study, to which an online questionnaire was applied, with 18 questions with one single option of answer. The results were statistically analysed.

Results and discussions. The obtained data show statistically significant results. The results regarding the knowledge about The Munsell Coloristic System show that the majority of the doctors are aware about this system. (85.7\%). The correlations between the doctor' $s$ age and his knowledge about this system, using the Fisher's Exact Test show statistic significative differences $(p=0.029)$. Using the same test, for the question regarding the most important colour characteristic from the 3 of them, statistic significative differences were obtained $(p=0.042)$, doctors from the smallest age groups were the most well trained.

Conclusions. The selection of the tooth colour is process influenced by subjective and objective factors (tooth colour knowledge) that can be improved.
\end{abstract}

Keywords: tooth colour selection, Munsell system, professional experience

\section{REZUMAT}

Obiective. Scopul studiului nostru a fost de a de a analiza gradul de cunoaștere al caracteristicilor culorii dentare de către medicii stomatologi din punctul de vedere al saturatiei, nuantei și luminozitătii, în corelatie cu diverși factori. Material şi metodă. 50 de medici stomatologi, cu un număr variabil de ani de practică stomatologică, având vâr-ste între 24 şi 54 ani, majoritatea de sex feminin, au constituit lotul de studiu, căruia i-a fost aplicat un chestionar online, cu un număr de 18 întrebări cu variantă unică de răspuns. Rezultatele au fost supuse analizei statistice. Rezultate şi discuţii. Datele obținute arată corelații semnificative statistic. Astfel, în ceea ce privește rezultatele privind cunoașterea sistemului coloristic Munsell, majoritatea medicilor cunosc acest sistem (85,7\%). Corelațiile dintre vârsta medicului și cunoștințele despre sistemul Munsell, folosind testul Fisher's Exact Test, arată existența unor diferențe semnificative $(p=0,029)$. Utilizând același test, la întrebarea referitoare la cea mai importantă caracteristică a culorii dentare dintre cele 3 cunoscute, au fost obținute diferențe semnificative statistic, $p=0,042$, medicii din cea mai mică grupă de vârstă fiind cei mai instruiți.

Concluzii. Alegerea culorii dentare cu ajutorul cheilor de culori este un proces influențat de factori subiectivi și obiectivi (cunoștințe despre culoare și caracteristicile ei) ce poate fi îmbunătățit.

Cuvinte cheie: alegerea culorii dentare, sistemul Munsell, experiență profesională 


\section{INTRODUCERE}

Alegerea culorii dentare este realizată ideal conform standardelor CIE (Commision Internationale de L'Ecleirage) pentru determinarea obișnuită a unor culori din pictură și conform sistemului Munsell (1), care însumează cele trei caracteristici ale culorii: luminozitatea (value), culoarea de bază (chroma) și saturația (hue) (2,3). Paleta de culori a dinților naturali se situează în zona de galbengalben-roșu a sistemului Munsell.

Acest sistem este reprezentat de un cerc care conține 100 de puncte împărțite în cinci culori principale - roșu, galben, verde, albastru și violet - și cinci culori secundare reprezentate de combinațiile dintre cele două culori vecine. Astfel, se deduc cele trei caracteristici ale culorii (7). Tridimensional vorbind, Hue reprezintă nuanța din paleta orizontală de culori principale, Chroma semnifică saturația culorii sau cât de mult gri conține culoarea, iar Value este coloana verticală care sugerează cât de mult alb sau cât de mult negru este într-o culoare (11). Alegerea culorii garniturii de dinţi artificiali la pacientul edentat total se realizează cel mai frecvent cu ajutorul cheilor de culori corespunzătoare firmei producătoare sau altor chei existe în majoritatea cabinetelor stomatologice. Pentru restaurările indirecte realizate în laborator sau pentru alegerea nuanței garniturii de dinți artificiali, în general se folosesc cheile Vitapan şi Vita 3D Master (5).

Cheia Vitapan classic conține 16 mostre de culoare divizate în patru grupuri corespunzătoare unei zone de culoare din sistemul Munsell: A corespunde roșu-galben, $\mathrm{B}$ galben, $\mathrm{C}$ gri, iar D gri-roșugalben. Valorile de la 1 la 4 notate pe mânerul culorii reprezintă gradul saturației culorii (4). De exemplu, mostra A3 semnifică nuanța roșu-galben şi saturaţia cu valoarea 3 .

De asemenea, culoarea dinților extrași anterior etapelor destinate realizării unei proteze totale poate fi determinată cu ajutorul instrumentelor moderne (spectrofotometre) (6). În mod ideal, alegerea culorii dentare se realizează independent de variabilele care pot apărea în cabinetul dentar, iar acest deziderat poate fi atins prin utilizarea tehnicilor obiective și reproductibile de determinare cu ajutorul dispozitivelor moderne de care dispune tehnologia actuală.

Medicul va alege cu ajutorul cheii de culori, în mod subiectiv, culoarea dentară pe care o consideră potrivită cazului clinic. Pornind de la aceste premise, scopul studiului nostru a fost de a de a analiza gradul de cunoaștere a caracteristicilor culorii dentare de către medicii stomatologi din punctul de vedere al saturației, nuanței și luminozității, în principal în corelație cu vârsta și experiența profesională, în cazul unor pacienți edentați total protezați.

\section{MATERIAL ŞI METODĂ}

Metoda de colectare a datelor studiului a fost reprezentată de distribuirea online a unui chestionar pe care 1-am realizat cu ajutorul aplicației Google Forms, intitulat „Considerații privind alegerea culorii dentare în protezarea totală“" și distribuit către 50 de medici stomatologi cu vechime variabilă în practica clinică.

\section{STRUCTURA CHESTIONARULUI}

Chestionarul cuprinde 18 întrebări cu variantă unică de răspuns. Primele trei întrebări furnizează date demografice și despre practica stomatologică. Întrebările 4 și 5 se referă la cunoștințele medicului despre caracteristicile culorii conform sistemului Munsell. Întrebările 6 și 7 furnizează informații despre instrumentele de alegere a culorii utilizate de medicii stomatologi respectivi în cabinetul stomatologic. Întrebările 8-15 oferă informații cu privire la percepția medicului asupra caracteristicilor culorii dentare, prin intermediul unor fotografii care expun zâmbetul a trei pacienți edentaţi total protezaţi.

Ultimele trei întrebări se referă la capacitatea medicului de a stabili culoarea dinților celor trei cazuri prezentate la întrebările anterioare, prin variante de răspuns reprezentate imagistic, fiecăruia corespunzându-i o mostră de culoare din cheia Vitapan Classic.

Baza de date obținută a fost analizată din punct de vedere statistic de către un statistician acreditat, care a utilizat următoarele programe și teste computerizate: programul Fisher's Exact Test, testele Z cu corecție Bonferroni, testul Shapiro-Wilk și testului Kruskal-Wallis H, realizând corelații între răspunsurile obținute.

\section{REZULTATE ŞI DISCUȚII}

Datele socio-demografice și practica stomatologică ale medicilor chestionați sunt următoarele: 
majoritatea au vârsta cuprinsă între 24 şi 34 de ani $(69,4 \%)$, sunt de sex feminin $(63,3 \%)$ și au o vechime mică, de $1-5$ ani $(63,3 \%)$.

În ceea ce privește rezultatele privind cunoașterea sistemului coloristic Munsell, la întrebarea „Cunoașteți cele 3 caracteristici ale culorii conform sistemului Munsell, respectiv nuanța, saturația și luminozitatea/strălucirea?", majoritatea medicilor au afirmat că știu despre sistemul Munsell $(85,7 \%)$. Distribuția medicilor raportată la frecvența răspunsului corect pentru întrebarea „Din cunoștințele dumneavoastră, care dintre cele trei caracteristici este cea mai importantă în alegerea culorii dentare?" arată că doar doar $36,7 \%$ dintre medici au răspuns corect. Distribuția medicilor raportată la cheia de culori utilizată mai frecvent arată că majoritatea medicilor utilizează cheia de culori Vitapan Classic $(79,6 \%)$. Corelațiile dintre vârsta medicului și cunoștințele despre sistemul Munsell, conform rezultatelor expuse anterior, arată că, dintre cei 50 de medici examinați, un număr considerabil de mare $(86 \%)$ au răspuns afirmativ la întrebarea referitoare la cunoașterea sistemului coloristic Munsell (întrebarea nr. 5). Cu toate că noțiunile despre sistemul Munsell aplicabile în stomatologie datează de mai bine de 50 de ani, iar tehnologiile actuale de determinare a culorii se bazează și acum pe cele trei caracteristici principale ale culorii, am observat în urma studiului că există medici care nu le cunosc. Dintre medicii care au răspuns afirmativ, majoritatea au avut vârste cuprinse între 24 și 34 de ani. Prin urmare, vârsta a influențat semnificativ frecvența cunoașterii sistemului Munsell. Datele din tabelul 1 reprezintă distribuția medicilor raportată la vârstă și cunoașterea sistemului Munsell. Diferențele între grupuri au fost testate folosind testul Fisher's Exact Test, rezultatele dovedind existența unor diferențe semnificative $(p=0,029)$.

TABELUL 1. Distributia medicilor raportată la vârstă şi cunoaşterea sistemului Munsell

\begin{tabular}{|l|c|c|c|c|c|}
\hline $\begin{array}{l}\text { Categorie de vârstă/ } \\
\text { Cunoaștere sistem } \\
\text { Munsell }\end{array}$ & \multicolumn{2}{|c|}{ Prezentă } & \multicolumn{2}{|c|}{ Absentă } & p* \\
\cline { 2 - 5 } & Nr. & Procent & Nr. & Procent & \\
\hline $\mathbf{2 4 - 3 4}$ ani & 31 & $74 \%$ & 3 & $49 \%$ & \multirow{2}{*}{$\mathbf{0 , 0 2 9}$} \\
\hline $\mathbf{3 5 - 4 4}$ ani & 6 & $13 \%$ & 2 & $25,5 \%$ & \\
\hline $\mathbf{4 5 - 5 4}$ ani & 6 & $13 \%$ & 2 & $25,5 \%$ & \\
\hline
\end{tabular}

*Fisher's Exact Test

$\mathrm{Cu}$ toate acestea, referitor la cunoașterea celei mai importante caracteristici ale culorii, majorita- tea de $44 \%$ au răspuns incorect că este culoarea de bază, doar 36\% au răspuns corect la întrebare (răspuns corect $\mathrm{C}$ : luminozitatea). Dintre medicii care au răspuns corect la această întrebare, cei mai mulți au vârste cuprinse între 24 și 34 de ani. Prin urmare, vârsta medicilor chestionați a influențat semnificativ frecvența răspunsului corect la această întrebare. Datele din Tabelul 2 reprezintă distribuția medicilor raportată la vârstă și frecvența răspunsului corect pentru întrebarea „Din cunoștințele dumneavoastră, care dintre cele trei caracteristici este cea mai importantă în alegerea culorii dentare?". Diferențele între grupuri au fost testate folosind testul Fisher's Exact Test, rezultatele dovedind existența unor diferențe semnificative $(81,2 \%$ vs. $47,1 \%)$.

TABELUL 2. Distribuția medicilor raportată la vârstă şi frecvența răspunsului corect pentru întrebarea „Din cunoştințele dumneavoastră, care dintre cele trei caracteristici este cea mai importantă în alegerea culorii dentare?"

\begin{tabular}{|l|c|c|c|c|c|}
\hline \multirow{2}{*}{ Criteriu / Vârstă } & \multicolumn{2}{|c|}{ Răspuns greșit } & \multicolumn{2}{|c|}{ Răspuns corect } & \multirow{2}{*}{ * } \\
\cline { 2 - 5 } & Nr. & Procent & Nr. & Procent & \\
\hline 24-34 ani & 8 & $47,1 \%$ & 26 & $81,2 \%$ & \multirow{2}{*}{$\mathbf{0 , 0 4 2}$} \\
\hline 35-44 ani & 5 & $29,4 \%$ & 3 & $9,4 \%$ & \\
\hline 45-54 ani & 4 & $23,5 \%$ & 3 & $9,4 \%$ & \\
\hline
\end{tabular}

*Fisher's Exact Test

Din aceste două corelații semnificative se poate deduce faptul că medicii tineri au avut acces la mai multe informații despre estetica dentară și interesul mai mare al acestora pentru aspectele estetice față de medicii cu vârste mai înaintate.

Alegerea culorii dentare reprezintă un proces important, care trebuie realizat în anumite condiții şi depinde de mai mulţi factori. Studiile demonstrează faptul că, deși instrumentele moderne de determinare a culorii au câștigat teren, cel mai frecvent utilizate sunt cheile de culori, care în ultimii 50 de ani nu s-au schimbat considerabil din punctul de vedere al caracteristicilor. Tehnicile moderne de determinare a culorii, utilizate în special la nivelul dinţilor naturali în scop protetic, aduc numeroase beneficii și se apreciază că vor fi utilizate mult mai des decât în prezent (11).

Un lucru interesant descoperit în urma acestui studiu, dar, totodată, destul de previzibil datorită avansării tehnologiei stomatologice, este faptul că medicii cu vârsta între 35 şi 44 ani utilizează camera digitală semnificativ mai mult $(66,7 \%)$ compara- 
tiv cu cheia de culori $(12,5 \%)$, în timp ce între medicii cu vârsta între 45 şi 54 de ani utilizează spectrofotometrul cu o frecvență semnificativ mai mare $(50 \%)$ comparativ cu cheia de culori $(10 \%)$. Datele din Tabelul 3 reprezintă distribuția medicilor raportată la vârstă și tipul instrumentului pentru alegerea culorii dinţilor. Diferențele între grupuri au fost testate folosind testul Fisher's Exact Test, rezultatele dovedind existența unor diferențe semnificative $(\mathrm{p}=0,014)$, confirmate de testele $\mathrm{Z}$ cu corecție Bonferroni.

TABELUL 3. Distribuția medicilor raportată la vârstă şi tipul instrumentului pentru alegerii culorii dinților

\begin{tabular}{|l|c|c|c|c|c|c|c|}
\hline \multirow{2}{*}{$\begin{array}{l}\text { Instrument/ } \\
\text { Vârstă }\end{array}$} & \multicolumn{2}{|c|}{$\begin{array}{c}\text { Cameră } \\
\text { digitală }\end{array}$} & \multicolumn{2}{c|}{$\begin{array}{c}\text { Cheie de } \\
\text { culori }\end{array}$} & \multicolumn{2}{|c|}{$\begin{array}{c}\text { Spectro- } \\
\text { fotometru }\end{array}$} & \multirow{2}{*}{ p* } \\
\cline { 2 - 7 } & Nr. & Procent & Nr. & Procent & Nr. & Procent & \\
\hline $\mathbf{2 4 - 3 4}$ ani & 1 & $33,3 \%$ & 31 & $\mathbf{7 7 , 5 \%}$ & $\mathbf{2}$ & $33,3 \%$ & \\
\hline $\mathbf{3 5 - 4 4}$ ani & 2 & $\mathbf{6 6 , 7 \%}$ & 5 & $\mathbf{1 2 , 5 \%}$ & 1 & $16,7 \%$ & $\mathbf{0 , 0 1 4}$ \\
\hline $\mathbf{4 5 - 5 4}$ ani & 0 & $0 \%$ & 4 & $\mathbf{1 0 \%}$ & 3 & $\mathbf{5 0 \%}$ & \\
\hline
\end{tabular}

*Fisher's Exact Test

TABELUL 4. Corelația dintre vârsta medicilor şi numărul răspunsurilor corecte din chestionar

\begin{tabular}{|l|l|}
\hline Corelație & $p^{*}$ \\
\hline $\begin{array}{l}\text { Scor_răspunsuri }\left(p=0,005^{* *}\right) x \\
\text { Vârstă }\left(p<0,001^{* *}\right)\end{array}$ & $0,005, R=0,394$ \\
\hline
\end{tabular}

*Spearman's rho Correlation Coefficient,

**Shapiro-Wilk Test
Datele din Tabelul 4 reprezintă corelația dintre vârsta medicilor și numărul răspunsurilor corecte din chestionar. Totalul răspunsurilor corecte a fost calculat pentru fiecare medic și identificat printr-un scor: scor_răspunsuri. Distribuția variabilelor este nonparametrică conform testului Shapiro-Wilk ( $p<$ $0,01)$. Corelația observată a fost semnificativă și pozitivă de grad moderat $(\mathrm{p}=0,005, \mathrm{R}=0,394)$ astfel că, în lotul analizat, vârsta înaintată a medicilor s-a asociat cu o frecvență mai mare a răspunsurilor corecte din chestionar.

TABELUL 5. Distribuția medicilor raportată la vechime şi numărul răspunsurilor corecte din chestionar

\begin{tabular}{|l|c|c|c|}
\hline Vechime & Medie \pm SD & Rang mediu & \multirow{2}{*}{$\mathrm{p}^{*}$} \\
\hline $1-5$ ani $\left(\mathrm{p}=0,002^{* *}\right)$ & $4,4 \pm 2,044$ & 21,03 & \multirow{3}{*}{0,087} \\
\cline { 1 - 3 } $5-10$ ani $\left(\mathrm{p}=0,039^{* *}\right)$ & $6 \pm 2,236$ & 32,14 & \\
\cline { 1 - 3 } $10-20$ ani $\left(\mathrm{p}=0,147^{* *}\right)$ & $5,14 \pm 1,215$ & 28,57 & \\
\hline$>20$ ani $\left(\mathrm{p}=0,967^{* *}\right)$ & $6 \pm 1,581$ & 33,8 & \\
\hline
\end{tabular}

Datele din tabelul 5 și figura 2 reprezintă distribuția medicilor raportată la vechime și numărul răspunsurilor corecte din chestionar. Distribuția a fost în general nonparametrică conform testului Shapiro-Wilk $(\mathrm{p}<0,05)$ și, de asemenea, nesimetrică conform reprezentării box-plot, de aceea, raportarea rezultatelor va utiliza rangul mediu al numă-

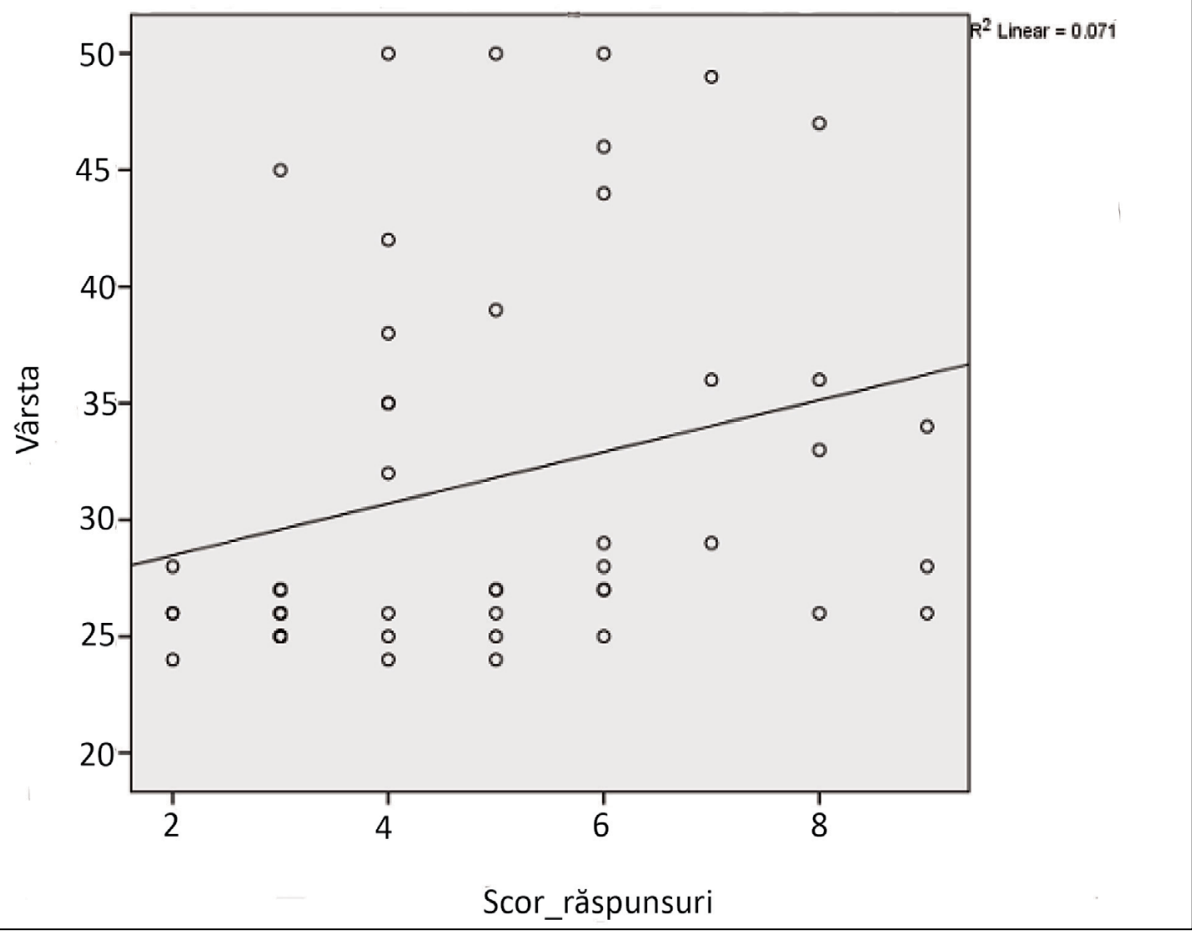

FIGURA 1. Graficul distribuției răspunsurilor corecte în funcție de vârsta medicilor 


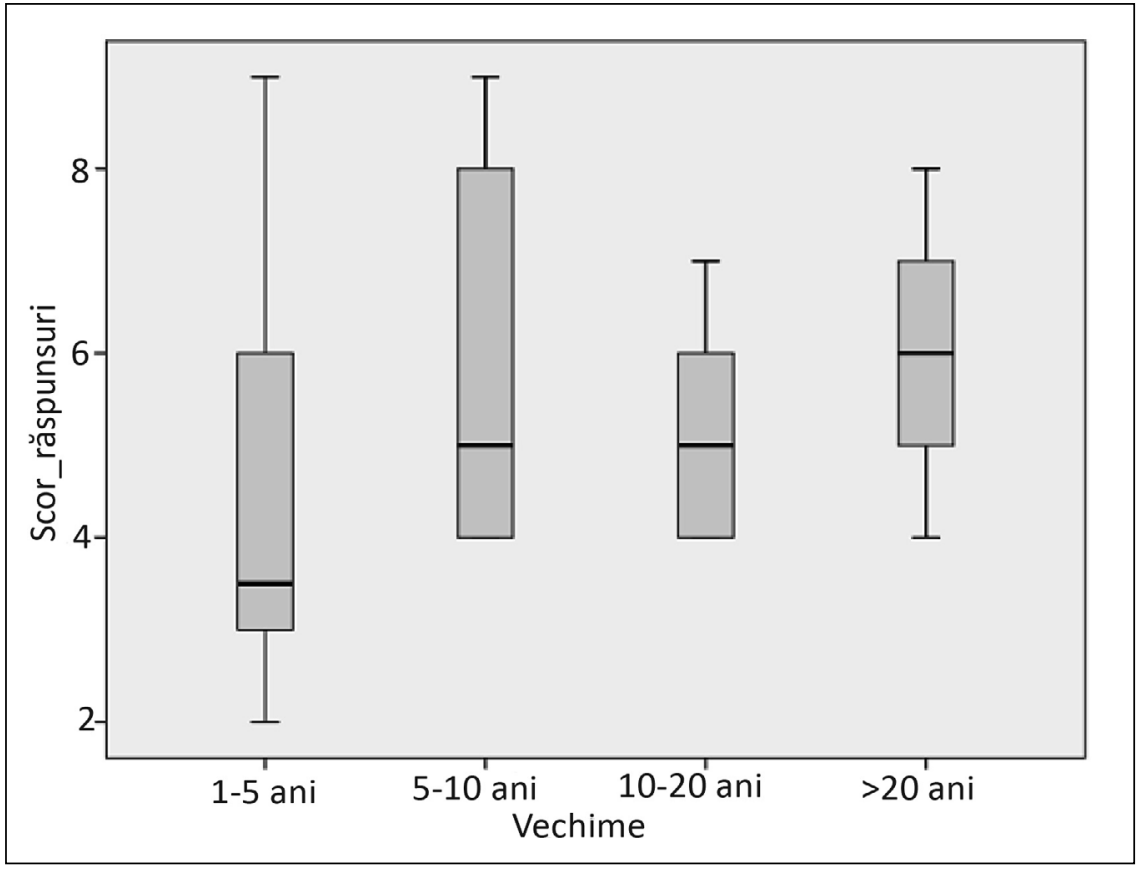

FIGURA 2. Distribuția medicilor raportată la vechime şi numărul răspunsurilor corecte din chestionar rului răspunsurilor corecte. Conform testului Kruskal-Wallis $\mathrm{H}$, diferențele observate nu au fost semnificative $(p=0,087)$, astfel că frecvența răspunsurilor corecte nu a fost influențată semnificativ de vechimea în practica stomatologică (în lotul analizat).

Rezultatele studiului nostru, în ceea ce privește corelarea capacităţii de luare a culorii dentare cu sexul și experiența profesională, sunt în concordanță cu mai multe studii pe teme similare. Astfel, studiul colectivului condus de Haddad H., Jakstat H.A. şi colab. (8), din 2009, pe un lot reprezentativ de medici stomatologi cu experiență și studenţi la medicină dentară din mai multe țări, a concluzionat că nivelul de experiență și sexul practicianului nu sunt factori care influențează alegerea culorii dentare. De asemenea, studiul din august 2019 (9), al colectivului format din Kumar K.A. şi colab., pe un lot de 100 de profesionişti din domeniul medicinei dentare (studenți şi medici stomatologi), a concluzionat că experiența profesională și sexul nu joacă un rol important în alegerea culorii în protetica dentară şi în stomatologia restaurativă.

În ceea ce privește sexul practicienilor, studiul colectivului de cercetare de la City University din Londra, condus de Rodríguez-Carmona M. (10), concluzionează că, din punct de vedere genetic, există diferențe de percepție cromatică între femei şi bărbați, rezultate din evaluări prin mai multe metode (CAD colour vision test, Nagel anomaloscope), dar concluzii ferme pot fi posibile prin obținerea și analiza datelor moleculare genetice a participanților la astfel de studii.

\section{CONCLUZII}

Cunoașterea caracteristicilor culorii în vederea obținerii unor restaurări dentare de nivel estetic ridicat este una dintre cerințele esențiale ale practicii stomatologice. Folosirea mijloacelor clasice - cheia de culori Vita - rămâne o alternativă viabilă, în condițiile însuşirii cunoștințelor legate de caracteristicile culorii dentare. Tehnologiile de determinare a culorii dentare nou introduse - spectrofotometru și camera digitală - reprezintă instrumente utilizate pe o scară din ce în ce mai largă de către clinicieni, în special de cei cu experienţă profesională mai mică. Subliniem astfel necesitatea familiarizării unui număr cât mai mare de practicieni atât cu noțiunile de bază ale culorii dentare, cât și cu folosirea tehnicilor moderne. 


\section{BIBLIOGRAFIE}

1. Joiner A. Tooth colour: A review of the literature. Journal of Dentistry. 2004; 32:3-12.

2. McLaren $\mathrm{K}$. Colour space, colour scales and colour difference. In: McDonald R, editor. Colour physics for industry. Huddersfield: $\mathrm{H}$. Charlesworth \& Co Ltd; 1987. p. 97-115.

3. Brainard DH. Colour Appearance and Colour Difference Specification, The Science of Colour (2 ed.). Elsevier, 2003, p. 202-206.

4. Petre A, Ioniță Petre, Trăistaru T. Criteriile estetice în medicina dentară consemnate în literatura de specialitate. Revista Română de Stomatologie, Vol. LVII, Nr.4, 2011, p. 283-285.

5. Okubo SR, Kanawati A, Richards MW, Childress S. Evaluation of visual and instrument shade matching. J Prosthet Dent 1998; 80:642-8.

6. Drăghici R, Preoteasa CT, Țâncu AMC, Preoteasa E. Dental Colour Assessment trough TTB exercises. Journal of Medicine and Life Vol. 9, Issue 1, January-March 2016, pp.61-65.
7. Chu SJ, Trushkowsky RD, Paravina RD. Dental colour matching instruments and systems. Review of clinical and research aspects. Journal of Dentistry 2010, 38, e2-e16.

8. Haddad HJ, Jakstat HA, Arnetzl G, Borbely J et al. Does gender and experience influence shade matching quality? Journal of Dentistry 2009. 37, e40-e44.

9. Kumar KA, Venkitachalam R, Athira R, Rahul S, Reshma S. The effect of gender and clinical experience on shade perception. Journal of Esthetic and Restorative Dentistry, August 2019.

10. Rodriguez Carmona ML, Sharpe LT, Harlow JA, Barbur JL. Sex-related differences in chromatic sensitivity. Visual Neuroscience 2008, 25(3), pp. 433-440.

11. Tâncu AM, Marin M, Preoteasa E, Meleșcanu Imre M, Preoteasa CT. The improvement of the aesthetic aspect and quality of life of the edentulous patients with the use of the modern colour determination techniques. Journal of Medicine and Life 2011, Vol. IV, Special Issue, 100-108 